Open Access

\title{
A review of Jonathan J. Webster and Xuanwei Peng (eds.), Applying Systemic Functional Linguistics: the state of the art in China today. London \& New York: Bloomsbury Academic, 2017
}

Jian Lu(D)

Correspondence: lujianfl@163.com School of Foreign Languages, Sun Yat-sen University, Guangzhou 510275, China

\begin{abstract}
The present paper is to review Applying Systemic Functional Linguistics: the state of the art in China today, a volume to highlight the contribution of Chinese scholars to the development of systemic functional linguistics.
\end{abstract}

As the title of this volume suggests, it is intended to showcase the current situation of systemic functional linguistics (hereafter SFL) research in China. Apart from a foreword by Guowen Huang, an editors' preface as well as an introduction by Zhuanglin $\mathrm{Hu}$, the collection comprises 21 chapters. The first two chapters, with M.A.K. Halliday and J.R. Martin as the author respectively, function as comments about the present state of the art in China and suggestions for its future development. The other chapters, written by representative Chinese systemicists, underline two viewpoints: SFL as a general linguistics and SFL as an appliable linguistics. The chapters cover a wide range of topics in the field with different methodologies. It is noticeable that systemicists in China have made an effort in applying SFL to the study of the Chinese language and are actively embracing new methodologies related to linguistic research.

Part 1 includes two chapters providing outside-in perspectives on the status quo in China. Halliday in the first chapter discusses contributions of linguistics in China to the development of SFL and stresses that it is important for systemicists to do comparative and typological studies since SFL, as a general linguistics drawing a distinction between theoretical and descriptive categories (Matthiessen et al., 2010: 76), views language as a meaning potential and represents it as networks of system. Chapter 2 by Martin mainly concerns how to train research students in SFL in China and suggests that SFL teachers in China adapt Rose's teaching/learning cycles (p.27) as part of their advanced coursework program and attach greater importance to applications.

Apart from an introduction by Zhuanglin $\mathrm{Hu}$, Part 2, showcasing the state of the art in China, consists of 19 chapters, which are organized into 13 sections. Section 1 deals with graphology and phonology. Based on the metafunction hypothesis, Chapter 3 by Xuanwei Peng presents a systematic description of the stroke systems of Chinese

(C) The Author(s). 2017 Open Access This article is distributed under the terms of the Creative Commons Attribution 4.0 International License (http://creativecommons.org/licenses/by/4.0/), which permits unrestricted use, distribution, and reproduction in any medium, provided you give appropriate credit to the original author(s) and the source, provide a link to the Creative Commons license, and indicate if changes were made. 
characters in their simplified regular script. As the first step toward the rank hierarchy of Chinese writing, Peng argues that this will be insightful to the study of other writing systems. Chengyu Liu in Chapter 4, with the help of a corpus-based description, aims to illustrate how a three-dimensional rank-metafunction-delicacy matrix works effectively in the analysis of modern Chinese modal particles which are often employed to supplement the intonation system as an important aspect of the Mood and Modality system of modern Chinese.

Two chapters in the next section are devoted to lexis. In Chapter 5, drawing on a corpus-based cluster analysis of 60 verbs which are selected from 444 verbs listed under the category of "emotion" or "affect", Chengfang Song makes a distinction between the so-called emotion verbs and emotional verbs, specifying their different grammatical patternings and behaviors. The following chapter, by Guoyan Lv \& Yanmei Gao, analyzes the process types and incident structure of a fiction by using the coding tool, BFSU Qualitative Coder 1.1 (p.91) to show that clausal constituents mark different phases of an incident.

Section 3 deals with nominal and verbal groups. Chapter 7 starts with a brief introduction to the well-known typological distinction between classifier and non-classifier languages, with English and Chinese as their typical member respectively. Bingjun Yang in this chapter argues against this distinction by presenting the similarities in structure and function of measure nominals in English and Chinese. He holds that the study of measure words has to take context into account and that potential contexts and principles of identification should be categorized from the perspective of SFL. The next chapter, by Wei He \& Ruizhi Ma, seeks to construct an overall Chinese temporal system in the light of SFL, including the tense types and instantiations. Guided by the principle of "meaning prior to form", the authors investigate grammatical or semi-grammaticalized resources of marked Chinese tenses construing the deictic relationship(s) between the event and its reference time(s). They also categorize tense in Chinese into primary tense, secondary tense, primary-secondary tense and secondary-secondary tense.

The fourth section is related to clause and clause complex. Guowen Yang in Chapter 9 discusses range characteristics in material clauses in Mandarin Chinese by comparing its grammatical behavior with that of goal and its counterpart in English. Range, specifying the domain of a process, is semantically not an inherent participant and syntactically more dependent on Process. It is more likely to be realized by nominals in Chinese and less likely to follow the preposition $b a ̆$ (把) in the b̌a (把) construction and fill in the thematic slot in the bèi (被) construction. Chapter 10, by Fu-mei Hsu, explores characteristic properties of the clause complex in Chinese. It is argued that parataxis appears more commonly than hypotaxis in Chinese. Issues related to the use of zero anaphora and nominal groups as clauses are also discussed within the framework of interdependency and logico-semantic relations.

$\mathrm{Li} \mathrm{Yu}$ and her colleagues in Chapter 11, Section 5 describe the generic distribution differences of Appraisal categories in the ten genres of English texts. This study is based on the Chinese-English Parallel Corpus of Appraisal Meanings, an annotated corpus developed by Xuanwei Peng and his research team. Generic distributions of appraisal in general as well as across 26 subcategories are examined and the statistics show that there exist significant differences between some genres particularly in terms of Attitude and Engagement. 
From a systemic typological perspective, Ping Wang in Chapter 12 addresses two questions: how is the meaning of Person realized through lexical and grammatical resources across languages and how do the two kinds of realization complement each other? The discussions are conducted from three aspects: lexicalization in terms of entity, Process and quality; grammaticalization in terms of personal pronoun, clitic, affix and zero form; and migration along lexis-grammar continuum (Halliday, 2008b: 33). It is suggested that different strategies of Person meaning construal, both lexical and grammatical, are involved to constitute a balanced entirety for the system of Person.

Chapter 13 approaches the issue of the disciplinary status of semiotics. With regard to the agony and crisis of semiotics, Zhuanglin $\mathrm{Hu}$ maintains that semioticians would have different perspectives on the role of semiotics and therefore propose various criteria to account for the disciplinary status of it. He attributes the flourishing of semiotics in the last two decades to the development of science and technology. Realizing a new trend of integration, he calls for the complementary relation between general semiotics and applied semiotics.

The following three chapters in connection with multimodality constitute Section 8 . Delu Zhang in Chapter 14 studies lexicogrammar and text in multimodal discourse analysis. It is suggested that the ways of analyzing multimodal texts should be appropriate for their composition in terms of the roles of different modes that realize them. The next chapter by Yumin Chen attempts to investigate multimodal construction of dialogic engagement in the context of teaching English as a foreign language. Four types of multimodal resources as engagement devices are identified, i.e. labeling, dialog balloons, jointly-constructed texts and illustrations. In addition, voice interaction is explored in relation to contact/observe, social distance and point of view. These discoveries facilitate the understanding of dialogic process in multimodal pedagogic context. Chapter 16, by Xiran Yang \& Jonathan J. Webster, is intended to study meaningmaking in Japanese shonen manga, a particular type of multimodal narrative, by relating meaning-making in manga reading to readers' eye movements. The top-down framework is SFL-based while the bottom-up data are collected through the methodology of eye tracking. As is reported, fixations and saccades function on different levels of metafuctions which are realized by different patterns of visual weaving.

Chapter 17 by Shisheng Liu \& Chengfang Song first proposes a revised semiotic model of multimodal art and semiotic modes (p.268) to observe how symbolic articulation mediates between theme and verbalization in multimodal texts. With an illustrated version of Shi Shuō Xīn Yũ as data for analysis, ways of illustrating in terms of image-text relations and ways of explicating in terms of manners of articulation are discussed.

Guowen Huang in Chapter 18 addresses issues of metafunctional equivalence in translated texts, using as an example the translated texts of a section in the Confucian Lun $Y u$. Based on the linguistic analysis, Huang proposes the order of importance of metafunctional equivalence: experiential metafunction $>$ interpersonal metafunction $>$ logical metafunction>textual metafunction. It is also maintained that equivalence is a matter of degree and different text types may require different degrees of effort in achieving equivalence.

Chapter 19 by Yinghui Sun \& Zhiqin Ju discusses genres in Chinese students' MA theses. With special reference to five typical genres of a thesis, a contrastive analysis between theses written by Chinese students of English and native English students is 
carried out. The study shows that overuse of some unnecessary phases and elements and avoidance of some necessary ones are the major problems. In order to help Chinese students with composition of academic articles, a schema for MA thesis writing cycle (p.317) is elaborated.

In Chapter 20, Chenguang Chang explores the insights gained from SFL into the compilation of an English-Chinese leaner's dictionary of English idioms. He argues that (i) apart from ideational meaning, interpersonal and textual ones should also be taken into consideration in the definitions of idioms; (ii) all the elements in the microstructure of an entry can work together in the delineation of meaning; and (iii) the dictionary and the thesaurus as two methods for describing lexical items can be combined in terms of the macrostructure of an idiom dictionary.

The last chapter by Xinzhang Yang focuses on how chemistry knowledge is presented linguistically in textbooks. From the ideational perspective, the use of technical terms, grammatical metaphor and transitivity patterning is examined; from the interpersonal perspective, the use of modal adjuncts and personal pronouns is explored; and from the textual perspective, the use of multimodal resources is investigated. This study will be helpful for content-based instruction and have implications for classroom instruction and textbook writing.

\section{Conclusion}

The great diversity of topics in this volume indicates that Chinese systemicists have been doing significant research in various areas of SFL. Among other things, there are three points worth mentioning. Firstly, the chapters revolve around two motifs: SFL as a general linguistics (Huang, 2007) and SFL as an appliable linguistics (Halliday, 2008a). The contributions of systemic scholars in China are mainly devoted to the development of general linguistic theory and to the exploration of the appliability of systemic functional description (p.xxiv). Chapters relevant to the former are related to graphology and phonology, lexis, word group, clause and clause complex, text and typology whereas chapters related to the latter are concerned with semiotics, multimodality, stylistics, translation, teaching, lexicography and register variation.

The second point is that Chinese systemcists have made an effort to study Chinese from the systemic functional perspective and have actively embraced those new methodologies of linguistic research. Seven out of the 19 papers in this collection deal with various aspects of Chinese, whose discoveries are enlightening for our understanding of the theory in question as well as the language from a general linguistic perspective. Another three papers also select Chinese instances as data.

The final point concerns the issue of pedagogic application of SFL, which is highlighted by Martin as "less well-known in China than elsewhere" (p.28). The past three decades has witnessed considerably rapid development of education in China, including foreign languages teaching and learning. However, there seems to have been a neglect of correspondingly influential pedagogy-related projects or studies informed by SFL. Halliday (2016) sees all learning itself as linguistic activity and has constructed a language-based theory of learning. The success of genre-based pedagogy proposed and promoted by Martin and his colleagues (e.g. Martin, 2012, 2013) has significant implications for future work in this area. 
Acknowledgements

I would like to thank Dr. Shukun Chen for his helpful suggestions for improvements.

Funding

Not applicable.

\section{Availability of data and materials}

All the data and materials supporting the conclusions of the article are included within the article.

\section{Authors' contributions}

My major contribution is to recommend a volume which highlights the contribution of Chinese scholars to the development of systemic functional linguistics. The present review is completed by me without any reference to any other author except the original authors of the volume.

\section{Author's information}

Jian Lu is a PhD student of systemic functional linguistics in School of Foreign Languages, Sun Yat-sen University, China.

Ethics approval and consent to participate

Not applicable.

\section{Consent for publication}

Not applicable.

\section{Competing interests}

The author declares that he has no competing interests.

\section{Publisher's Note}

Springer Nature remains neutral with regard to jurisdictional claims in published maps and institutional affiliations.

\section{References}

Halliday, M.A.K. 2008a. Working with meaning: towards an appliable linguistics. In Meaning in context, ed. J.J. Webster. London \& New York: Continuum.

Halliday, M.A.K. 2008b. Complementarities in language. Beijing: The Commercial Press.

Halliday, M.A.K. 2016. In Aspects of language and learning, ed. J.J. Webster. Berlin \& Heidelberg: Springer-Verlag.

Huang, G. 2007. Systemic functional linguistics as a general linguistics theory. Foreign Languages in China 5: 14-19.

Martin, J.R. 2012. In Language in education, ed. Z. Wang. Shanghai: Shanghai Jiaotong University Press.

Martin, J.R. 2013. Genre-based literacy programmes: contextualizing the SLATE project. Linguistics and the human Sciences 7: 5-27.

Matthiessen, C.M.I.M., K. Teruya, and M. Lam. 2010. Key terms in systemic functional linguistics. Beijing: Foreign Language

Teaching and Research Press.

\section{Submit your manuscript to a SpringerOpen ${ }^{\circ}$ journal and benefit from:}

- Convenient online submission

- Rigorous peer review

Open access: articles freely available online

- High visibility within the field

- Retaining the copyright to your article

Submit your next manuscript at $\gg$ springeropen.com 